\title{
A STUDY FOR THE APPLICATION OF HACCP SYSTEM IN HAMA NATIVE SLAUGHTERHOUSE
}

\author{
R.W. DARWISH* and U. TURKMANE ${ }^{* *}$ \\ * Msc. In Vet. Med. \\ ${ }^{* *}$ Department of Zoonoses, Faculty of Vet. Med., Syria.
}

\section{ABSTRACT}

Received: 11/8/2012

Accepted at: 20/10/2012
This study was conducted to assess the technical specifications, and hygienic practices applied in Hama local slaughterhouse, to evaluate microbial contamination for all stages of slaughtering process, and to study the possibility of rehabilitation of the slaughterhouse for the application of HACCP system and to identify the points of weakness that prevent the application of the system in the slaughterhouse. The assessment of slaughterhouse showed that the percentage of the total score of application of GHP is 50\% reflecting medium hazard which directly affects the hygienic quality and microbiological specifications of the produced meat. On the other hand, the evaluation of some other practices such as cleaning and disinfection and all practices carried out prior to slaughter reflects high-hazard, because these were not conducted according to the GHP requirements which may affect both the quality and safety of the produced meat. Assessment of the technical requirements showed poor maintenance in all sections specially, These poor hygienic practices were evident on the high load of examined microorganisms in the produced meat. The study was also planned to determine the ways of developing slaughterhouse through application of HACCP system after the completion of prerequisites and training of workers and staffs is highly recommended.

Key words: HACCP, Meat hygiene, Disinfection.

دراسة لتطبيق نظام تحليل المخاطر لنقاط التحكم الحرجة بمسلخ حماه البلدي

$$
\text { ربيع واصل درويش ، عون تركمانسي }
$$

أجريت هذه الدر اسة بغرض تقييم الاشتر اطات الفنية و الممارسات الصحية المتبعة في حماه البلدي، ورصد التلوث الجرثومي بجميع مر احل الذبح

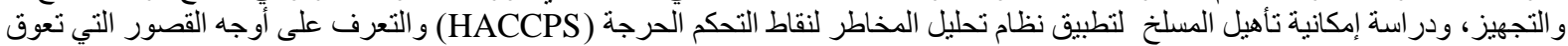

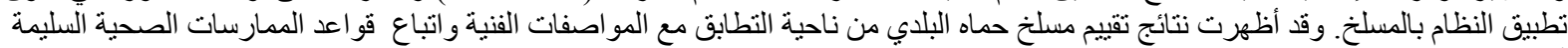

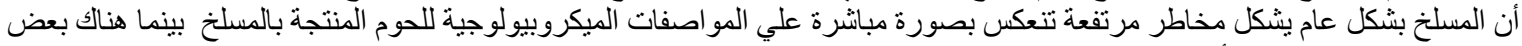

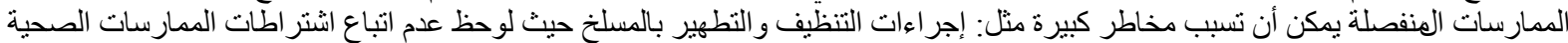

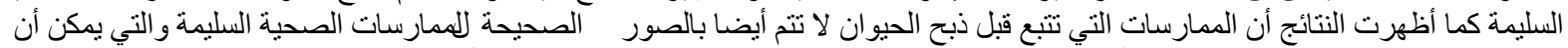

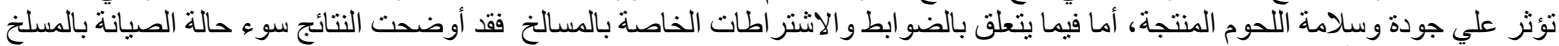

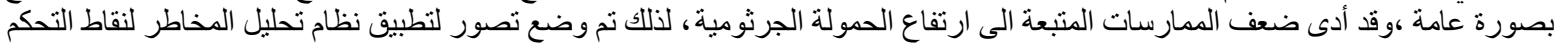

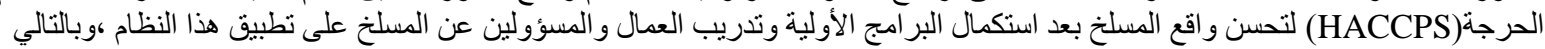
انخفاض الحمولة الجرثومية للذبائح .

كلمات مفتاحية :الهاسب: نظام تحليل المخاطر لنقاط التحكم الحرجة

\section{INTRODUCTION}

المقدمة

$$
\begin{aligned}
& \text { اهتم الاسلام بوضع أسس وقاعد صحة وسلامة الغذاء، فأحل الطيبات من الرزق .قال تعالى:(بأيها الذين امنو ا كلو من طيبات ما }
\end{aligned}
$$

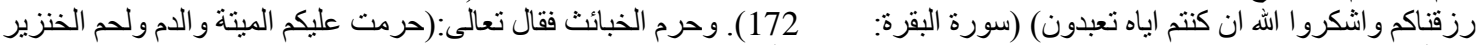

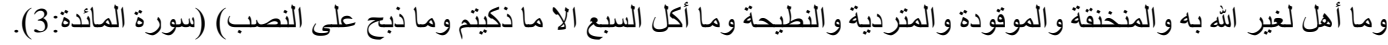




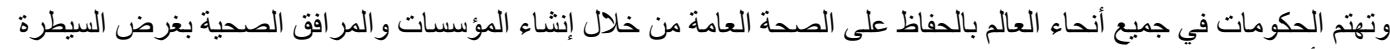

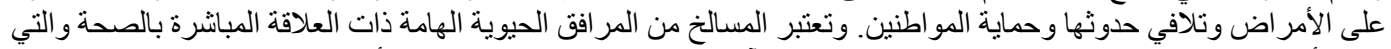

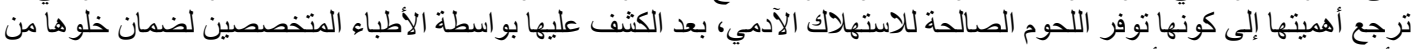
الأمر اض المشتركة والأمر اض المعدية.

لذللك فقد اهتمت الدول المتقدمة بوضع اشتر اطات للمسالخ يجب تو افر ها ممثلة في اختيار الموقع المناسب وتوفير المساحة والمر افق لقانق

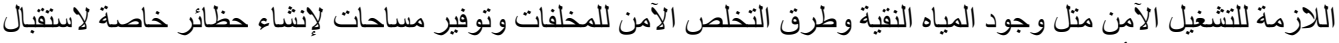
الحيو انات وحظائر أخرى لعزل الحيو انات المريضة و المشتبه بها (مرشدي 1418هـ و وSofos, 2008).

يتضح من هذا أن إنثاء المسالخ الحديثة أصبح ضرورة ملحة تقتضيها ظروف التطور المتلاحق و المتنامي لمو اجهة الزيادة الكبيرة

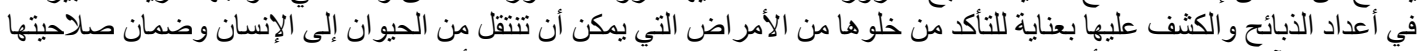

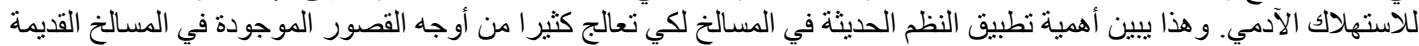

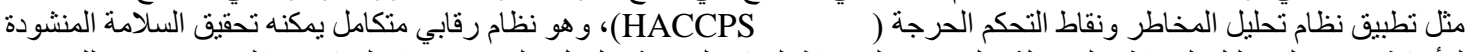

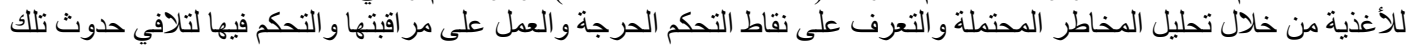

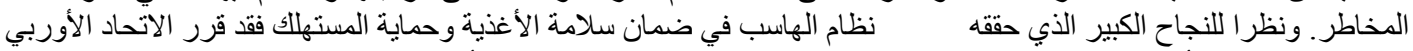

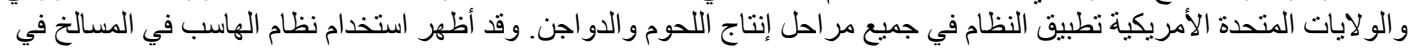

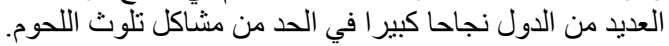

.(Bolton \& Sheridan 2002; Nastasijevic et al., 2008; Horchner et al., 2006)

بدأت فكرة نظام الهاسب عام 1960 عندما عهدت وكالة الفضاء الأمريكية ناسا الى شركة بيلز بيرى الأمريكية تطوير نظام يمنع

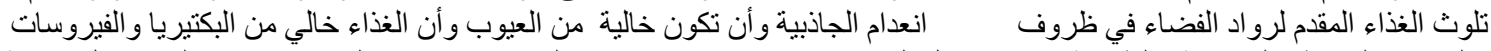

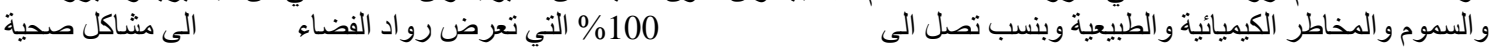

.(Satin.miriam,\& Maryland, U.S.A., 2002)

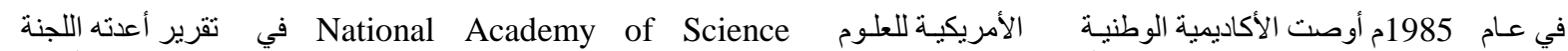

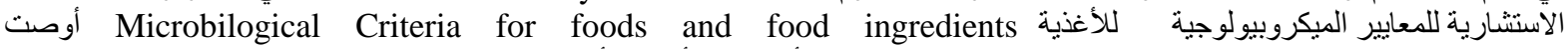

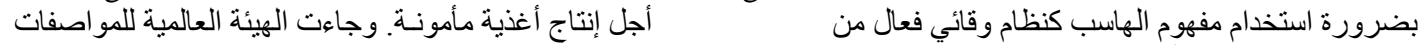

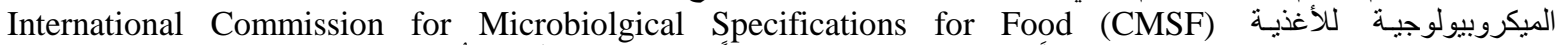

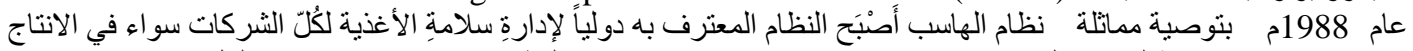

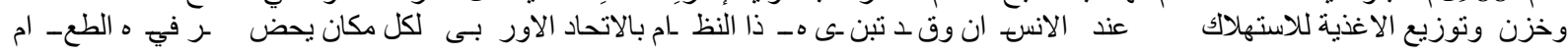
.(codex, 1993)

حيث أن استهلاك الأغذية الملوثة تسبب أمر اضيا عديدة ولاسيما منتجات الحيو انات وات وخصوصا اللحوم من حيو اناتات مصابة او جثث حاملة لجر اثيم

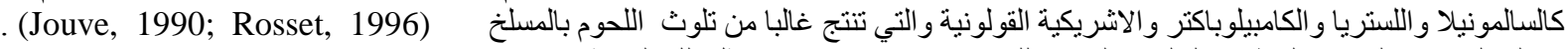

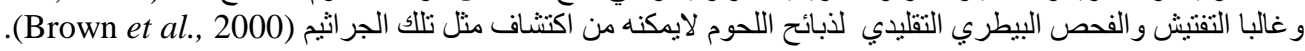

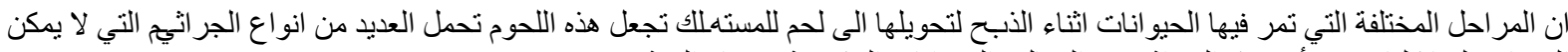

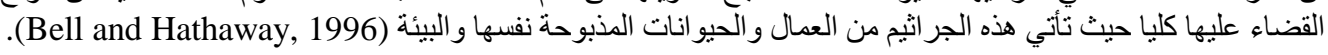

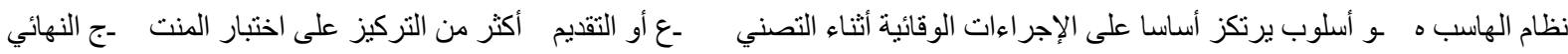
(Satin.miriam,\& Maryland, U.S.A., 2002) وهو نظام قابل للتطوير و التكييف مع أي تغييرات سواء كانت: في المعدات ،التصميم، الخطوات التصنيعية، أو التطورات التقنية.

أهداف البحث:

أجريت هذه الدراسة بهدف معرفة مدى اتباع الممارسات الصحية السليمة بمسلخ حماه البلدي ومدى توفر الاشتر اطات الفنبة والبرامج الأولية التي

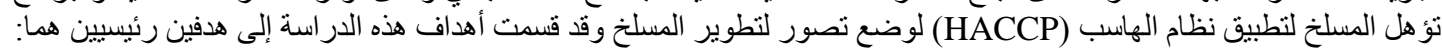

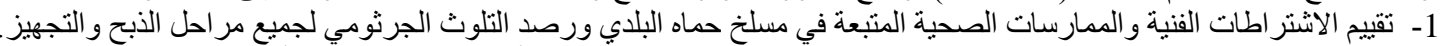
2- وضع تصور لتطوير المسلخ من خلال تطبيق نظام الهاسب بعد دراسة البرامج الأولية والتعرف على أوجه القصور التي تعوق تطبيق النظام.

\section{MATERIALS and METHODS} مواد وطرق البحث

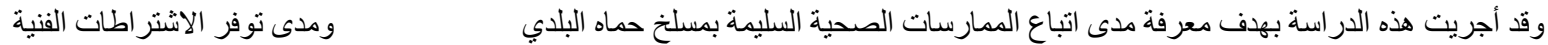

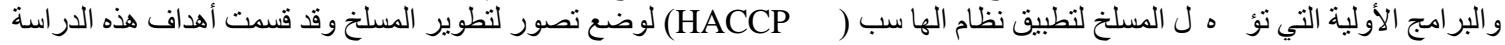

$$
\begin{aligned}
& \text { إلى هدفين رئيسيين هما: } \\
& \text { 1- 2 - رصد التلوث الميكروبي لجميع مر احل الذبح و التجهيز. }
\end{aligned}
$$

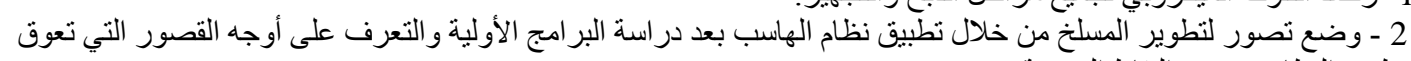

$$
\begin{aligned}
& \text { تطبيق النظام. وتحديد النقاط الحرجة. }
\end{aligned}
$$




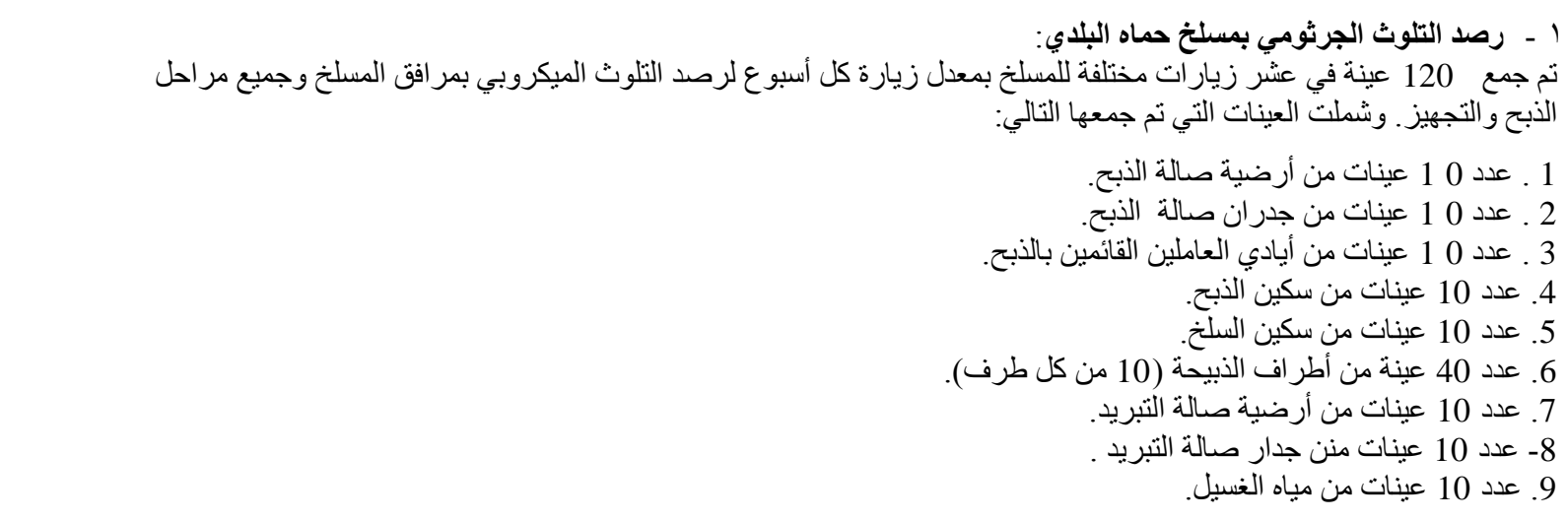

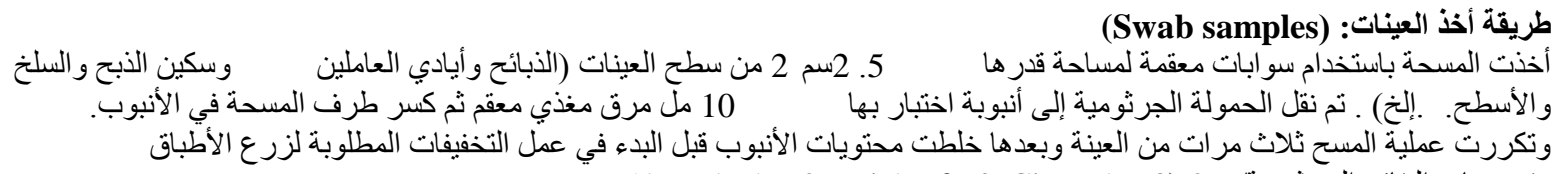

وتم حساب النتائج الجرثنومية/سم2 (APHA, 1992 and Arafa \& Chan, 1978).

الفحوص الميكروبيولوجية :

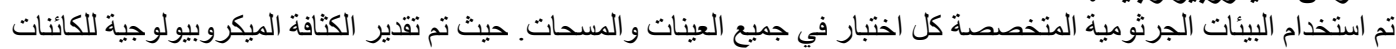

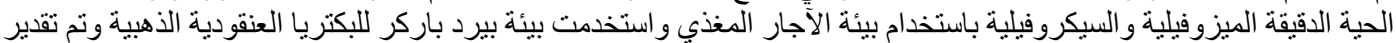

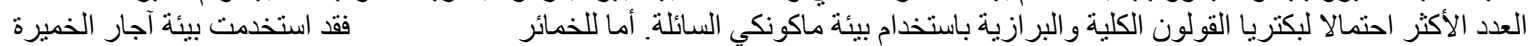
و الديكستروز (م.ق.س. 1996) و (APHA, 1992; Arafa \& Chan, 1978) .

\section{RESULTS النتائج}

المسلخ يقع بعيدا عن المحافظة حوالي 3-4كم في الناحية الشرقية منها ، ولا نوجد شكاوي من السكان حول التأثر بروائح المسلخ علما ان هذه المسافة كافية لتشتت الروائح.

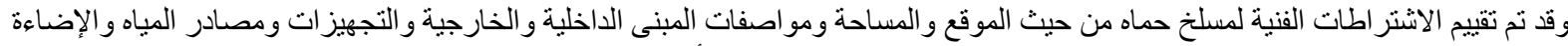

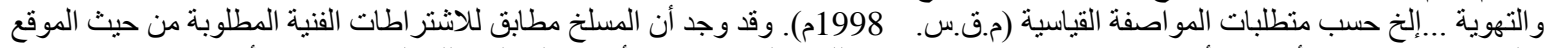

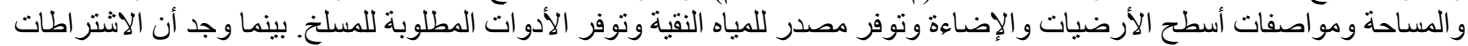

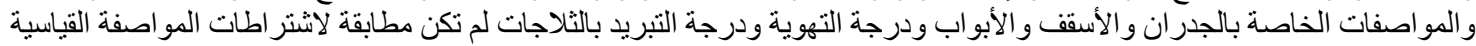

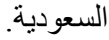

جدول (1): يوضح الكثافة الجرثومية لأماكن اخذ العينات في مسلخ حماه البلاي جميع مر احل الذبح:

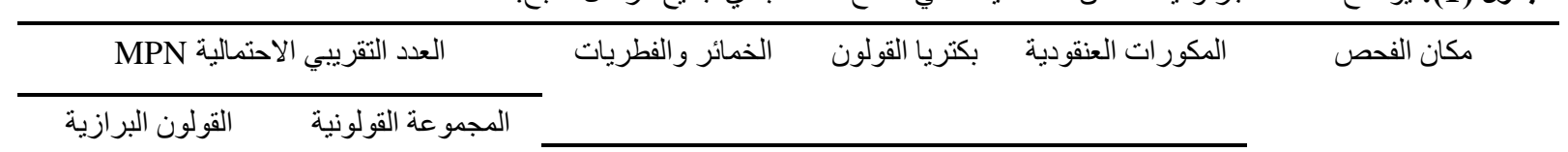

$\log \mathrm{cfu} / \mathrm{cm} 2(\mathrm{X} \pm \mathrm{SD})$

\begin{tabular}{|c|c|c|c|c|c|}
\hline $12.9 \pm 9.5$ & $34.02 \pm 29.3$ & $2.92 \pm 0.73$ & $2.26 \pm 0.31$ & $3.25 \pm 0.83$ & أرضية المسلخ \\
\hline $4.9 \pm 3.1$ & $11.9 \pm 3.4$ & $2.08 \pm 0.17$ & $2.15 \pm 0.31$ & $2.7 \pm 0.35$ & جدار المسلخ \\
\hline $2.53 \pm 4.25$ & $20.3 \pm 24.41$ & $3.68 \pm 0.72$ & $2.62 \pm 0.35$ & $3.24 \pm 0.77$ & أرضية الثلاجة \\
\hline $4.35 \pm 2.53$ & $9.09 \pm 7.88$ & $3.44 \pm 1.36$ & $2.00 \pm 0.28$ & $3.86 \pm 0.79$ & الجدار الداخلي للثلاجة \\
\hline $4.54 \pm 3.51$ & $10.49 \pm 7.82$ & $2.69 \pm 0.71$ & $2.14 \pm 0.39$ & $3.67 \pm 0.66$ & سكين الذبح \\
\hline $4.7 \pm 3.75$ & $10.43 \pm 7.77$ & $2.45 \pm 0.67$ & $2.07 \pm 0.38$ & $2.91 \pm 0.67$ & سكين السلخ \\
\hline $13.75 \pm 10.07$ & $36.85 \pm 35,26$ & $2.69 \pm 1.43$ & $2.31 \pm 0.50$ & $3.26 \pm 0.50$ & أيد العاملين \\
\hline $10.18 \pm 9.69$ & $29.54 \pm 35.52$ & $1.99 \pm 0.34$ & $2.59 \pm 0,54$ & $3.07 \pm 0.75$ & الطرف الأمامي الأيسر \\
\hline $8.25 \pm 8.41$ & $17.25 \pm 17.04$ & $2.09 \pm 0.43$ & $1.96 \pm 0.33$ & $2.60 \pm 0.48$ & الطرف الأمامي الأيمن \\
\hline $11.3 \pm 6.82$ & $31.05 \pm 21.41$ & $2.13 \pm 0.43$ & $2.22 \pm 0.33$ & $2.91 \pm 1.06$ & الطرف الخلفي الأيسر \\
\hline $4.7 \pm 3.2$ & $12.2 \pm 6.6$ & $1.92 \pm 0.36$ & $2.03 \pm 0.19$ & $2.36 \pm 0.65$ & الطرف الخلفي الأيمن \\
\hline- & - & - & - & - & مياه الغسيل \\
\hline
\end{tabular}


Assiut Vet. Med. J. Vol. 58 No. 135 October 2012

جذول (2) يوضح الكثافة الكليه للجر اثيم المحبة للبرودة ومعتدلة البرودة لأماكن اخذ العينات في مسلخ حماه البلدي جميع مر احل الذبح.

\begin{tabular}{|c|c|c|}
\hline \multicolumn{2}{|c|}{ الكثافة الجرثومية الكلية (total microbial count) } & \multirow[t]{2}{*}{ 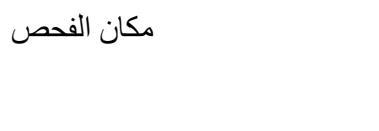 } \\
\hline المحبة للبرودة 20م & معتدلة البرودة 37مم & \\
\hline $3.2 \pm 0.88$ & $4.09 \pm 0.66$ & 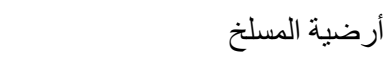 \\
\hline $2,97 \pm 0.83$ & $3.09 \pm 0.65$ & 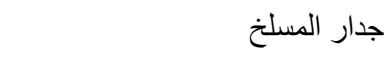 \\
\hline $4.94 \pm 0.88$ & $4.88 \pm 0.94$ & 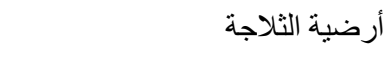 \\
\hline $3.8 \pm 1.05$ & $4.42 \pm 0.94$ & 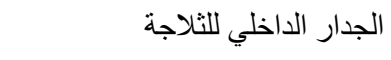 \\
\hline $3.36 \pm 0.98$ & $3.87 \pm 0.85$ & 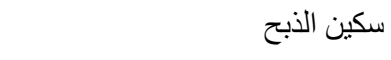 \\
\hline $3.1 \pm 0.74$ & $3.54 \pm 0.79$ & سكين السلخ \\
\hline $3.0 \pm 0.35$ & $3.61 \pm 1.01$ & 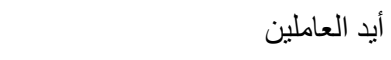 \\
\hline $3.11 \pm 0.67$ & $1.13 \pm 0.75$ & الطرف الأمامي الأيسر \\
\hline $2.65 \pm 0.61$ & $2.95 \pm 0.64$ & الطرف الأمامي الأيمن \\
\hline $2.93 \pm 0.64$ & $2.94 \pm 0.93$ & الطرف الخلفي الأيسر \\
\hline $2.41 \pm 0.39$ & $2.93 \pm 0.57$ & الطرف الخلفي الأيمن \\
\hline $2.14 \pm 0.49$ & $2.21 \pm 0.6$ & مياه الغسيل \\
\hline
\end{tabular}

\section{DISCUSSION}

المناقشة

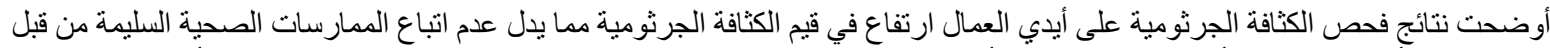

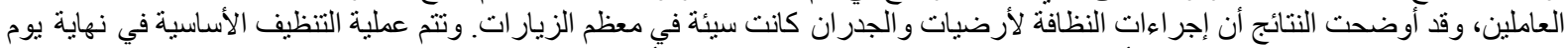

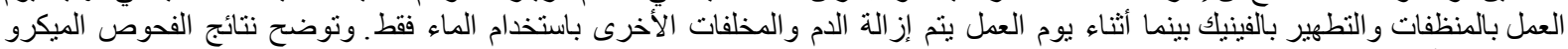

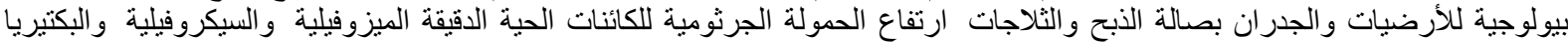
العنقودية وبكتيريا القولون الكلية و البرازية والخمائر والئر والفطريات مما يدل على عدم فاعلية عمليات التنظيف و التطهير بالمسلخ.

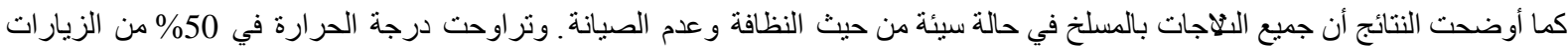

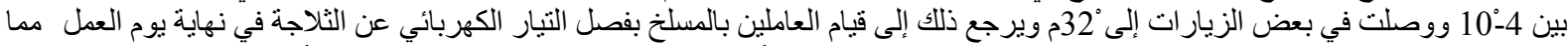

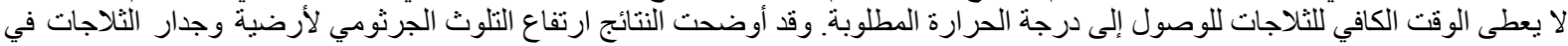

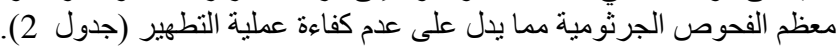

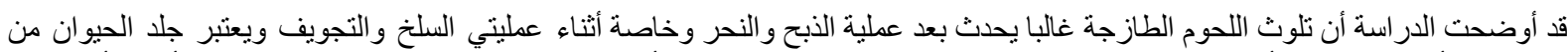

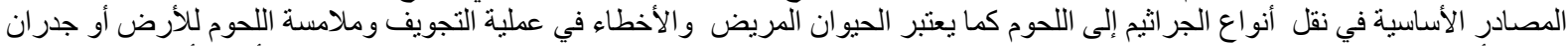

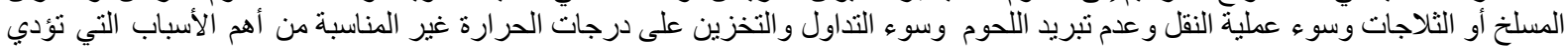

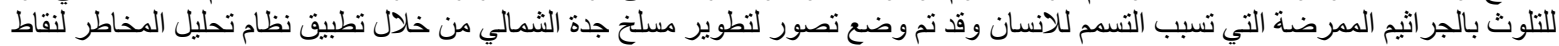

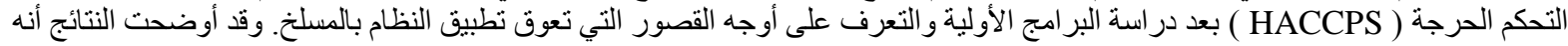
لتطبيق النظام يستلزم استكمال البر امج التالية:

1 ـ وضع برنامج متكامل للتنظيف و التطهير بجميع مر افق السلخ و الثلاجات و الأدواته بما في ذللك نظافة العاملين.

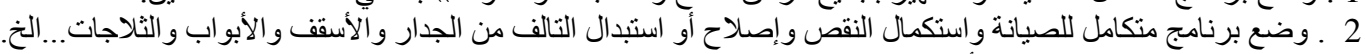

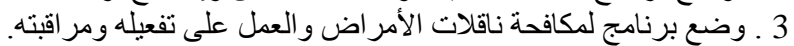
4 ـ وضع برنامج تدريبي للعاملين و الأطباء البيطريين.

وبالتالي هذا الجدول يوضح من خلاله كيفية تحليل المخاطر البيولوجية والكيميائية والفيزيائية بجميع مر احل انتاج اللحوم بالمسلخ واجر اءات التحكم و السيطرة. 
جدول (3): يوضح كيفية تطبيق نظام الهاسب في مسلخ حماه البلدي وتحليل المخاطر.

\begin{tabular}{|c|c|c|c|c|}
\hline \multirow[t]{2}{*}{ اجر اءات التحكم } & \multicolumn{2}{|l|}{ المخاطر المحتملة } & \multirow[t]{2}{*}{ مر احل الذبح } & \multirow{4}{*}{1} \\
\hline & الوصف & النوع & & \\
\hline 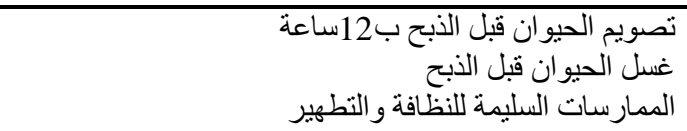 & ملوثات ميكروبية & ب & استلام الحيوان & \\
\hline شهادة من المورد بأبي علاج اعطي للحيوان وتاريخ & متبقيات الادوية البيطرية & ك & & \\
\hline شهادة من البيطري على الكيد الحيو الحيو ان من الامر اض & مختركة وجود أمر اض & ب & فحص الحيوان قبل & 2 \\
\hline- & لايوجد & ب & الادماء & 3 \\
\hline تنظيف وتعقيم أدو ات الذبح & الذبح ومن أرضية من صالة ألذبح & ب & ازلة الر أس والاقدام & 4 \\
\hline 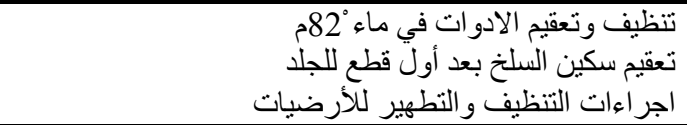 & 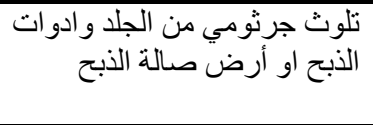 & ب & از الة الجلد & 5 \\
\hline 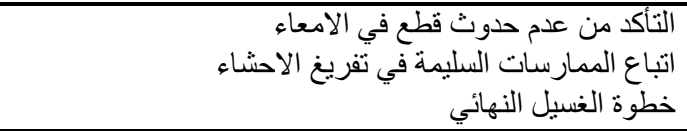 & تلوث جرثُومي من الامعاء & ب & از الة الاحشّاء & 6 \\
\hline وجر اء فحص شادة بيطرية بالخلو من الأمر اض الخد & مشتركة و غير هال الفمر اض اضل & ب & فحص الحيو ان بعد & 7 \\
\hline 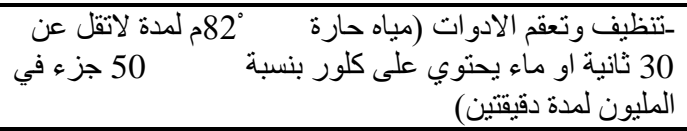 & و تلوث جرثومي من الادو ات & ب & القبيحمة وتقطيع & $\overline{8}$ \\
\hline 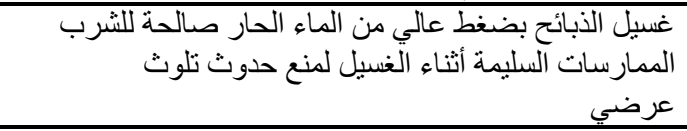 & من الخطو از الة التلوث جرثو السابقة & ب & اللذبيحة النهائي & $\overline{9}$ \\
\hline 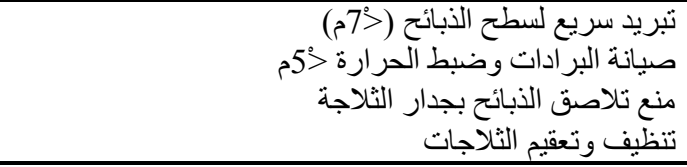 & 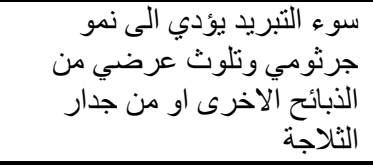 & ب & التبريد & 10 \\
\hline اتباع الممارسة الصحية السيارة الذبائح & العمال جرثومي من ايدي & ب & التحميل & 11 \\
\hline
\end{tabular}

Conclusions الاستنتاجات

يطبق العديد من الممارسات الصحية السليمة التي تضمن انتاج

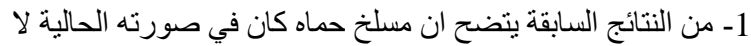
لحوم خالية من المخاطر الجرثة النومية.

ايتماثى مع ما توليه الدولة من اهتمام بقضية سلامة الغذاء

2- أن المسلخ كان يعاني من قصور في في نظام المر اقبة و التقتيش و هذال وصحة المو اطنين.

3- نسبة الخطورة في المسلخ مرتفعة قبل تطبيق نظام المر اقبة وهذا ما يشكل خطورة على صحة المستهلك الكئ.

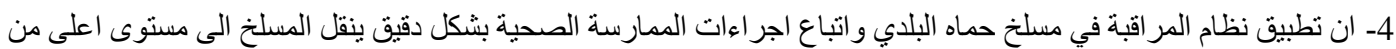

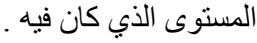
5- بتطبيق نظام المر اقبة في المسلخ لوحظ انخفاض في الحمولة الجرثومية وفروقات معنوية واضحة في أماكن أخذ العينات.

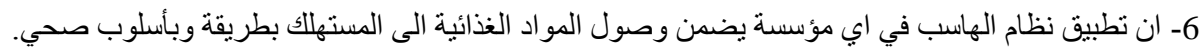

\section{Recommendations التوصيات}

1- المسلخ مزود بنظام الي للذبح ينلافى فيه العديد من الملوثات للحوم لكنه و اقف للأسباب فنية لذلك من الضروري اعادة تأهيل هذا النظام ومعاو دته للعمل.

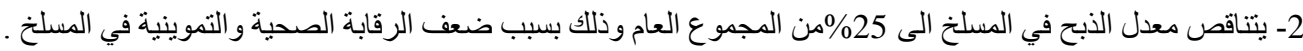

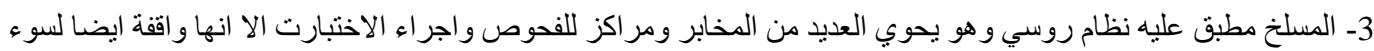

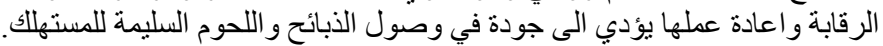




$$
\begin{aligned}
& \text { 4- تطبيق الهاسب كنظام وقائي في جميع مؤسسات دولة التي تعنى بتقديم الطعام للمستهلك باستمر ار ووجود رقابة دائمة ولجنة ادارة } \\
& \text { تعمل على تطبيق هذا النظام دائما. }
\end{aligned}
$$

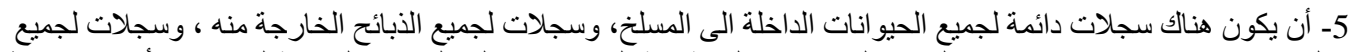

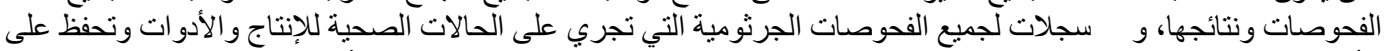

$$
\begin{aligned}
& \text { الأقل لمدة سنتين. وتحفظ نتائج الفحوصات الجرثومية للذبائح لمدة } \\
& \text { و العاملين. } \\
& \text { 6- يلزم أن يكون الماء المستخدم في المسالخ قابل للاستهلاك الآدمي. ويلزم تحليل المياه خلال فترات معينه لتحديد نو عية المياه. }
\end{aligned}
$$

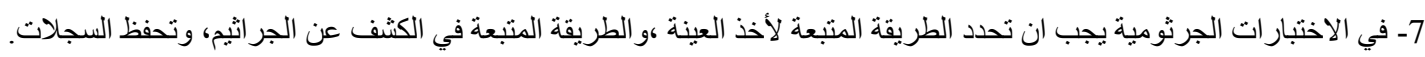

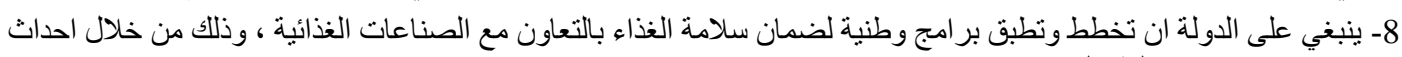

$$
\begin{aligned}
& \text { تشريعات وقو انين متعلقة بالغذاء. }
\end{aligned}
$$

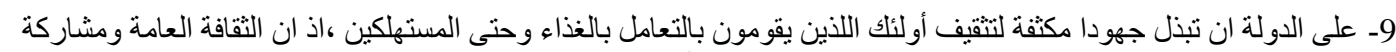

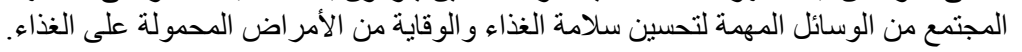

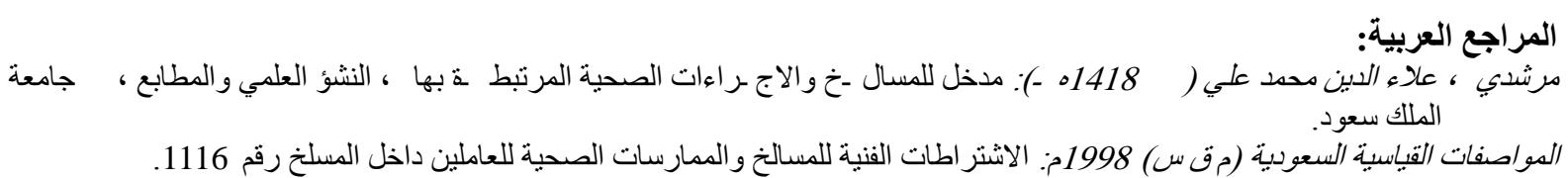

\section{REFERENCES}

APHA (1992): Compendium of Methods for Microbiology Examination of Foods, In: M.L. Speck(ed), American Public Health Association, Washington D.C., USA.

Arafa, A.S. and Chan, T.C. (1978): Ascorbic and dipping as a means of extending shelf-life and improving microbial quality of set-up broiler parts, Poultry Sci., 56: 99-103.

Bell, R.G. and Hathaway, S.C. (1996): The hygienic efficiency of conventional and inverted lamb dressing systems. Journal of Applied Microbiology. 81, pp. 225- 234.

Bolton, D.J. and Sheridan, J.J. (2002): HACCP for Irish Beef, Pork and Lamb Slaughter, Food Safety Department, The National Food Centre, Dublin.

Brown, M.H.; Gill, C.O.; Hollingsworth, J.; Nickelson, I.R.; Seward, S.; Sheridan, J.J.; Stevenson, T.; Sumner, J.L.; Theno, D.M.; Usborne, W.R. and Zink, D. (2000): The role of microbiological testing in systems for assuring the safety of beef. International Journal of Food Microbiology. 62, pp. 7- 16.

Codex (1993a): Draft revised code of hygienic practice for fresh meat. In: Report of the 7th Session of the Codex Committee on Meat Hygiene Alinorm 93/16A, Codex Alimentarius Commission, FAO, Rome, pp. 32-57.

Horchner, P.M.; Brett, D.; Gormley, B.; Jenson, I. and Pointon, A.M. (2006): HACCP-based approach to the derivation of an on farm food safety program for the Australian red meat industry, Food Control., 17: 497-510.

Jouve, J.L. (1990): Microbiologie alimentaire et filière viande. Viandes et Produit Carnés. 11, pp. 207- 213.

Nastasijevic, I.; Mitrovic1, R. and Buncic, S. (2008): Occurrence of Escherichia coli O157 on hides of slaughtered cattle, Applied Microbiology, 46: 126-131.

Rosset, R. (1996): Autres viandes et produits carnés. In: Bourgeois, C.M., Mescle, J.F., Zucca, J.,(Eds.), Microbiologie Alimentaire, Tome1, Aspect microbiologique de la sécurité et de laqualité des aliments. Lavoisier Tec et Doc, pp. 331- 346.

Satin miriam, and Maryland, U.S.A. (2002): (Quality Enhancement in Food Processing Through HACCP).

Sofos, J.N. (2008): Challenges to meat safety in the 21st century, Meat Science, 78: 3-13.Stinson, G.G. and Tiwari, N.P. (1978) Evaluation of quick bacterial count method from assessment of food plant sanitation, J. Food Protection, 41: 269-71. 